\title{
Preliminary investigation on the tribocorrosion behaviour of nanotubular structured Ti6Al4V surfaces
}

\author{
N.R. Rodrigues ${ }^{a}$, A.C. Alves ${ }^{a}$, F. Toptan ${ }^{a, b, *}$, L.A. Rocha ${ }^{b, c}$ \\ ${ }^{a}$ CMEMS-UMinho - Center for MicroElectroMechanical Systems, Universidade do Minho, Azurém, 4800-058 Guimarães, Portugal \\ ${ }^{\mathrm{b}}$ IBTN/Br - Brazilan Branch of the Institute of Biomaterials, Tribocorrosion and Nanomedicine, Bauru, SP, Brazil \\ ${ }^{c}$ UNESP_Univ. Estadual Paulista, Faculdade de Ciências de Bauru, Dep. Física, 17033-360 Bauru, SP, Brazil
}

\section{A R T I C L E I N F O}

\section{Article history:}

Received 11 July 2017

Received in revised form 30 October 2017

Accepted 15 November 2017

Available online 16 November 2017

Keywords:

Nanotubular structures

Ti6Al4V

Tribocorrosion

\begin{abstract}
A B S T R A C T
In order to improve its tribocorrosion resistance, nanotubular structures were produced on Ti6Al4V surfaces by anodic treatment in a mixture of $1 \mathrm{M} \mathrm{H}_{2} \mathrm{SO}_{4}$ and $0.08 \mathrm{M}$ HF electrolyte. Tribocorrosion tests were performed in a phosphate-buffered saline solution (PBS) against an alumina ball under $50 \mathrm{mN}$. Results showed that nanostructured surfaces exhibited significantly lower tendency to corrosion due to the protecting effect given by the well-adherent $\mathrm{TiO}_{2}$ nanotubular layer.
\end{abstract}

(c) 2017 Elsevier B.V. All rights reserved.

\section{Introduction}

Ti6Al4V alloy is one of the most popular material for the femoral stem in hip joint prostheses due to its high corrosion resistance, biocompatibility, and adequate mechanical properties. However, its poor wear resistance raises major clinical concerns as combined action of corrosion and wear (i.e. tribocorrosion) leading to the release of wear debris and metallic ions [1].

Recently, nanostructured $\mathrm{Ti}$ surfaces gained an intensive attention in order to improve biocompatibility, wear resistance, and osseointegration properties [2-4]. Within several available techniques, anodic treatment (AT) is a reliable, economic, and easy process enabling the growth of titanium oxide layer with nanotubular morphology $[5,6]$.

Studies showed that $\mathrm{TiO}_{2}$ nanotube arrays formed by AT exhibited better biological and antimicrobial properties [7,8], and better corrosion behaviour [9]. However, knowledge on the tribocorrosion behaviour of these surfaces are scarce. A recent study on the tribocorrosion behaviour of NT arrays formed on commercially-pure Ti surfaces showed that cracking and detaching of the NT arrays is critical for the tribocorrosion performance of these surfaces [10]. However, the tribocorrosion behaviour of NT arrays formed on Ti alloys is yet to be evaluated. Thus, the present

\footnotetext{
* Corresponding author at: CMEMS-UMinho - Center for MicroElectroMechanical Systems, Universidade do Minho, Azurém, 4800-058 Guimarães, Portugal.

E-mail address: ftoptan@dem.uminho.pt (F. Toptan).
}

study aimed at giving a first insight on the tribocorrosion behaviour of Ti6Al4V alloy having nanotubular $\mathrm{TiO}_{2}$ surfaces.

\section{Material and methods}

Grade 5 Ti6Al4V alloy samples (VSMPO TIRUS) were cut from $20 \mathrm{~mm}$ diameter bars to $4 \pm 1 \mathrm{~mm}$ height discs, ground through 1200 mesh SiC paper, ultrasonically cleaned in propanol for 10 min and distilled water for $5 \mathrm{~min}$. Afterwards, the samples (hereafter will be designated as ET) were etched in a solution of HF: $\mathrm{HNO}_{3}: \mathrm{H}_{2} \mathrm{O}$ with a volume ratio of $1: 1: 1$, during $5-8 \mathrm{~s}$ at room temperature, then ultrasonically cleaned following the procedure given above.

Nanotubular surfaces were obtained by anodizing the etched samples at constant voltage of $20 \mathrm{~V}$ (DC power supply GPR$30 \mathrm{H} 10 \mathrm{D}$ ) during 5 and $60 \mathrm{~min}$ in the electrolyte containing $1 \mathrm{M}$ $\mathrm{H}_{2} \mathrm{SO}_{4}$ and $0.08 \mathrm{M} \mathrm{HF}$ at room temperature where a Pt foil was used as a cathode (hereafter, the treated samples will be designated as 5AT and 60 AT, respectively).

Tribocorrosion tests were performed using a reciprocating tribometer (CETR-UMT-2) against $10 \mathrm{~mm}$ diameter alumina ball (Goodfellow) in PBS $\left(8 \mathrm{~g} / \mathrm{L} \mathrm{NaCl}, 0.2 \mathrm{~g} / \mathrm{L} \mathrm{KCl}, 1.2 \mathrm{~g} / \mathrm{L} \mathrm{Na}_{2} \mathrm{HPO}_{4}\right.$ and $0.2 \mathrm{~g} / \mathrm{L} \mathrm{KH}_{2} \mathrm{PO}_{4} ; \mathrm{pH}=7.4 \pm 0.04$ ). Samples (working electrode) were mounted in a three-electrode cell having a saturated calomel reference electrode (SCE) and a Pt counter electrode, connected to a Gamry Reference 600 Potentiostat/Galvanostat/ZRA. Experiments were performed at body temperature $\left(37 \pm 1{ }^{\circ} \mathrm{C}\right)$ under a normal load of $50 \mathrm{mN}$, total stroke length of $1 \mathrm{~mm}$, frequency of $1 \mathrm{~Hz}$, 

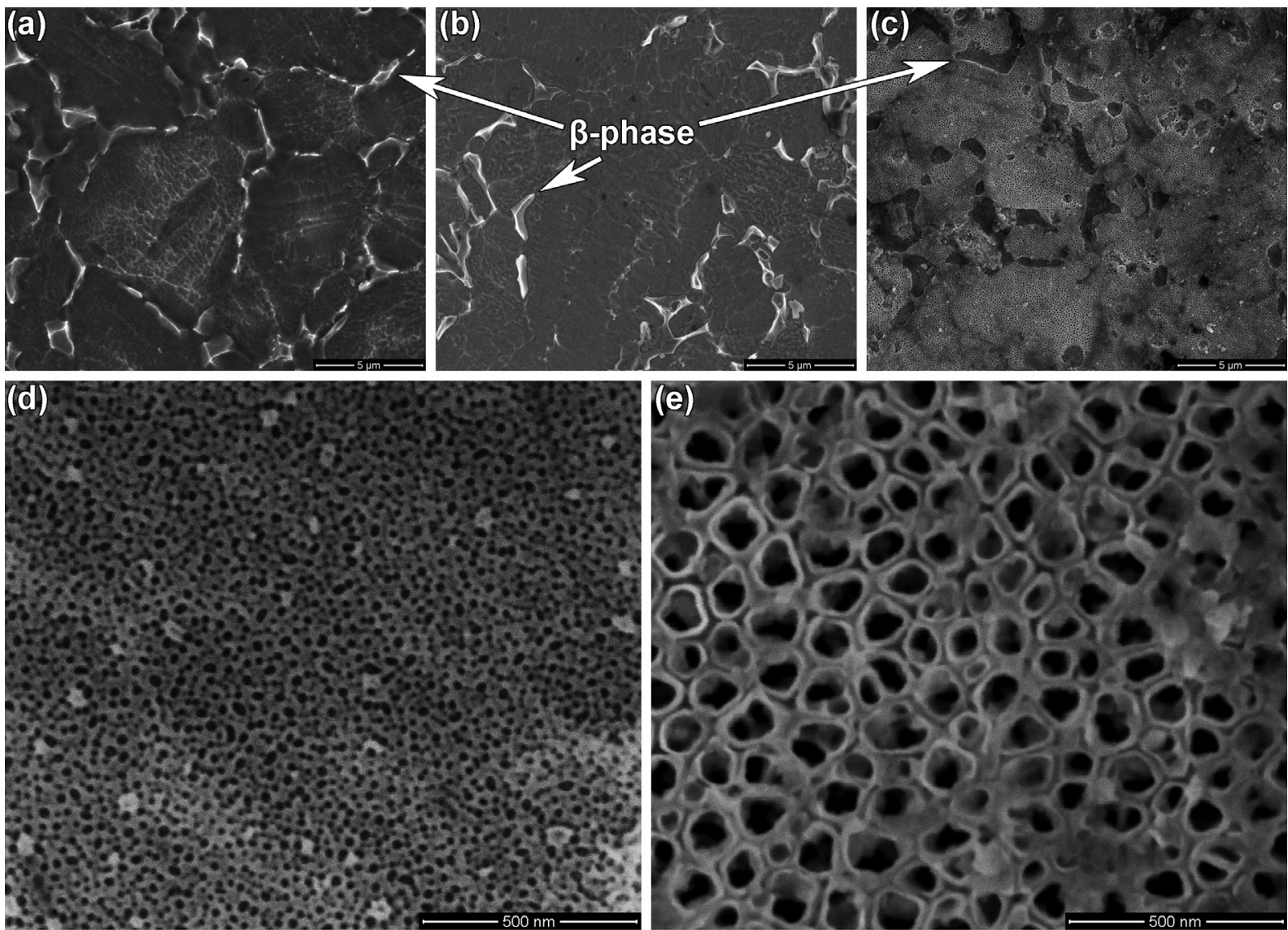

Fig. 1. SE-SEM images of a) ET, b) 5AT, and c) 60AT surfaces, together with detailed images taken from the $\alpha$-matrix of d) 5AT, and 4) $60 A T$ surfaces.

and sliding time of $1800 \mathrm{~s}$. After tests, samples were ultrasonically cleaned following the procedure referred above, and characterized using backscattered (BSE) and secondary electron (SE) detector signals under FEI Nova 200 FEG-SEM, equipped with EDAX EDS.

\section{Results and discussion}

Fig. 1 presents the SEM images of the sample surfaces before and after AT. Fig. 1a shows the typical morphology of ET sample with small dispersed irregular-shaped $\beta$-phase in the $\alpha$-phase matrix. 5 min of AT (Fig. 1b) resulted in the oxidation of the $\alpha$ phase (Fig. 1d), with the formation of randomly organized nanotubes of very small diameter $(<45 \mathrm{~nm})$. However, no nanotubes were formed in the $\beta$-phase. This can be explained by the fact that in the presence of the anodizing electrolyte (rich in fluoride ions) the $\beta$-phase dissolved faster than the $\alpha$-phase, the thickening of the oxide film being inhibited. After increasing the anodizing time to $60 \mathrm{~min}$ (Fig. 1c), the dissolution of the $\beta$-phase became obvious whereas the nanotubular morphology observed in the $\alpha$-phase (Fig. 1e) evolved to a self-organized nanotubular structure with higher pore diameter $(\approx 90 \mathrm{~nm})$, as also reported by Matykina et al.[11].

Fig. 2 gives the representative SEM images of the worn surfaces. ET samples exhibited well-reported worn surface features for this alloy, such as parallel sliding grooves (abrasive wear), and compacted oxidised wear debris. These features were not detected for AT samples where smoother surfaces were observed. Within AT samples, 5AT samples presented relatively narrower wear tracks, however, exhibited more severe plastic deformation as can be seen by smeared-smooth surface features (Fig. 2e).
Fig. 3a presents the evolution of open circuit potential (OCP) and coefficient of friction (COF). Before sliding, the stabilized potential values reflect the presence of a protective and stable film on the sample surface, namely a passive film for ET samples and nanotubular layers grown during AT. Stabilization potentials revealed that the presence of a nanotubular layer made the surface of the Ti6Al4V alloy nobler, displaying less tendency to corrosion. When sliding started, a sudden decrease was observed in the potential values of ET samples due to the damage given to the passive film. In the case of AT samples, the potential decay did not happen immediately on the onset of the sliding, instead, decreased slowly and the cathodic shift was significantly smaller, suggesting that the nanotubular layers were effective on protecting Ti6Al4V alloy from the triboelectrochemical action, under the studied conditions. After sliding, potential values were recovered near the initial values for all samples, due to repassivation, although the difference on the potential before, during and after sliding was not significant on 60AT samples.

Under sliding, AT samples presented lower COF as compared to ET samples that can be linked to the self-lubricating effect given by the anodic-treated surfaces [12]. Besides, comperative EDS analysis of the worn and unworn surfaces (Fig. $2 \mathrm{~b}$ and $2 \mathrm{c}$ ) revealed a noticeable difference on the oxygen content for ET samples that can be attributed to the formation of the oxidised wear debris that may result in increased COF by acting as third-body particles.

Based on these experimental results, the first insight on the tribocorrosion mechanism may be suggested as follows. On the onset of the sliding, ET samples exhibited an immediate cathodic shift due to the damage given to the native oxide film. After a run-in period (approx. $1 \mathrm{~min}$ ), these surfaces presented a recovery on the potential values till the end of sliding that can be related with 

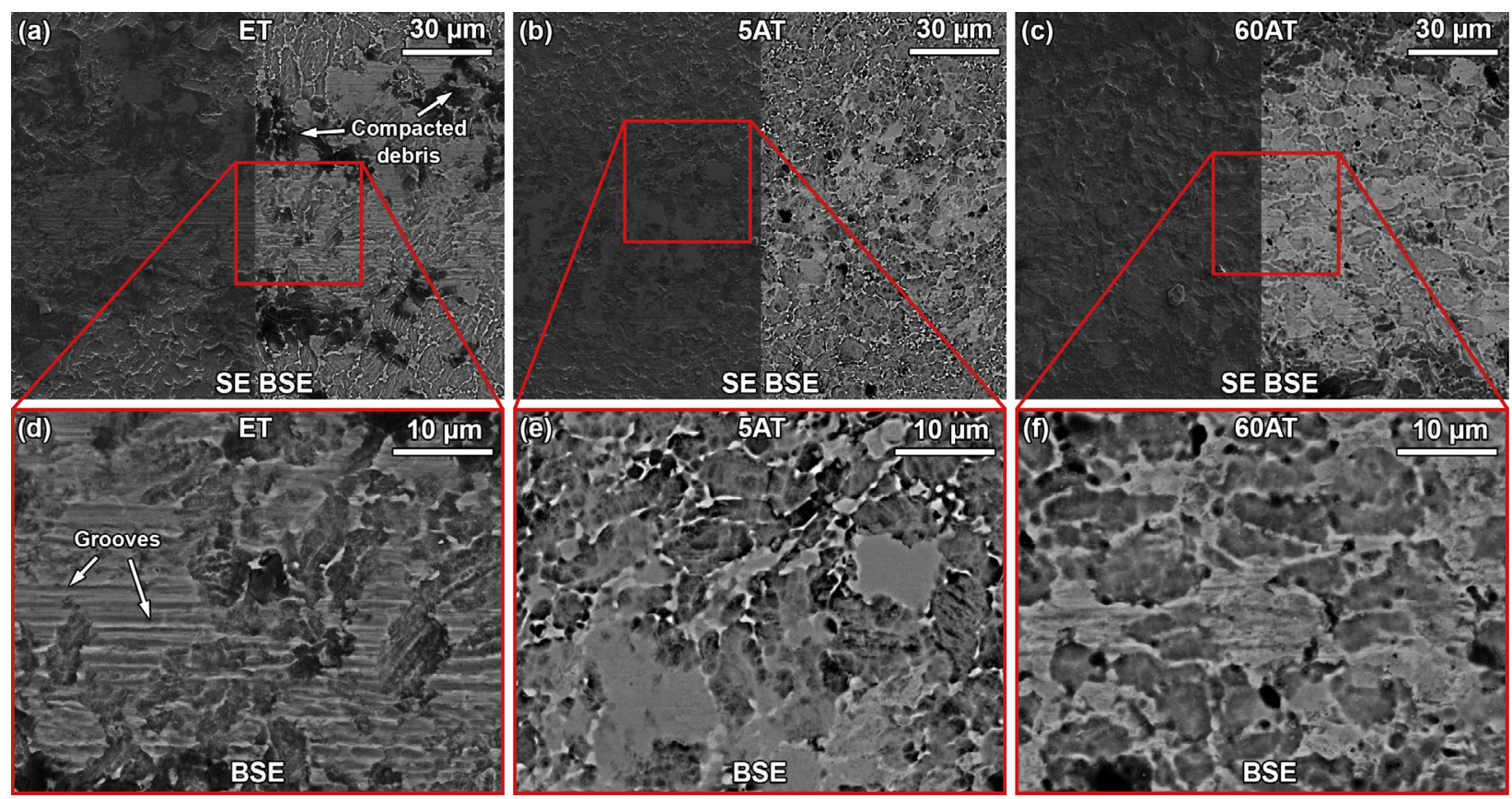

Fig. 2. Lower (a, b, c) and higher (d, e, f) magnification SEM images of ET, 5AT, and 60AT worn surfaces.
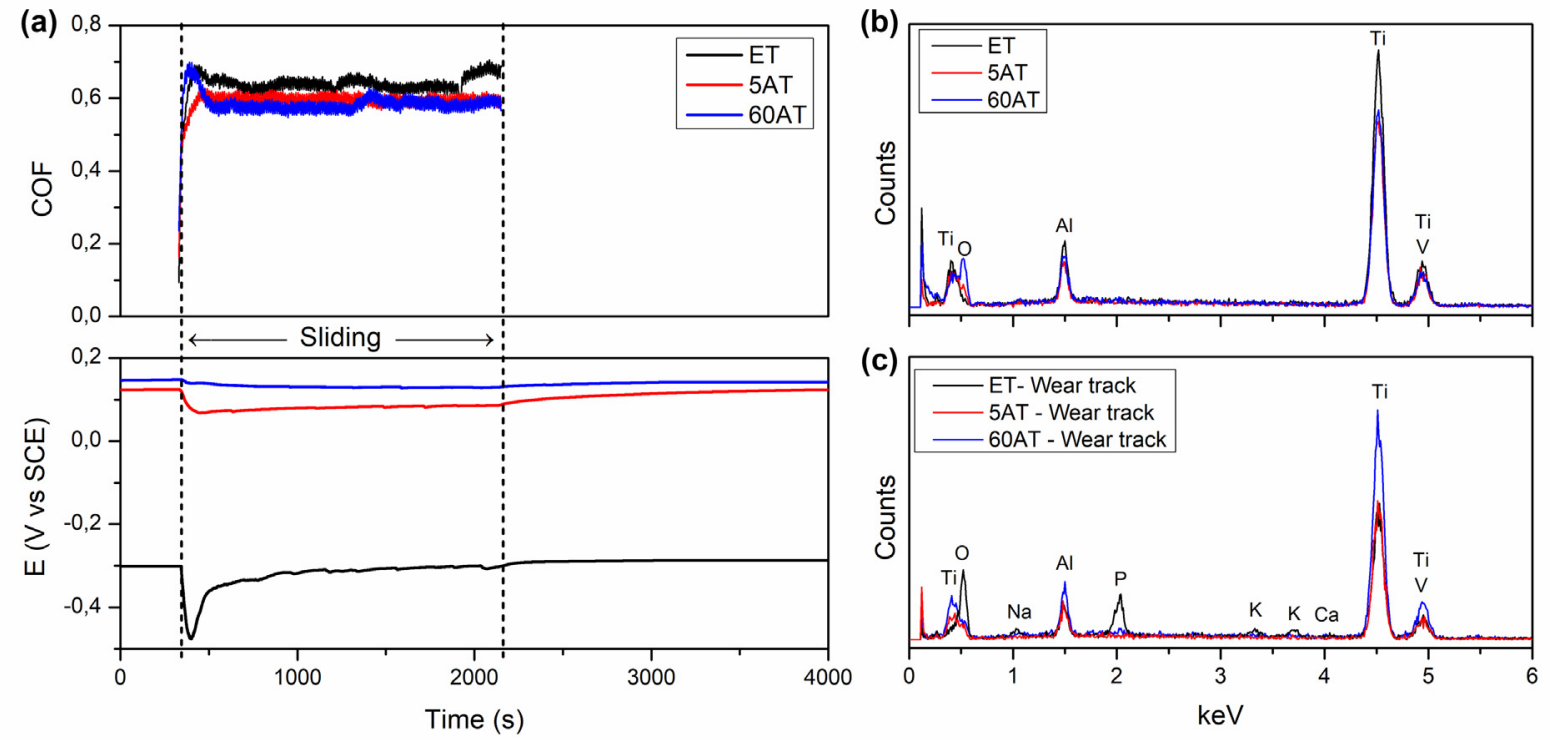

Fig.3. Evolution of OCP together with COF during sliding; EDS spectra of b) as-processed, and c) worn surfaces.

the formation of a compacted wear debris providing a limited protection [13]. AT samples presented less wear damage, together with lower cathodic shift on OCP and lower COF during sliding that may be linked to the improved load bearing ability of the nanotubular oxide layers, and their effect on reducing COF [12,14]. Considering that sliding did not significantly affect the OCP values, and caused less plastic deformation on 60AT samples, it can be suggested that the self-organized nanotubular morphology provided relatively improved tribocorrosion resistance. Even though, it is clear that the effect of crystallinity and crystalline structure [3], as well as the differences on the morphology or the thickness of the nanotubular layers to the tribocorrosion behaviour needs further studies including potentiostatic or potentiodynamic tribocorrosion tests in order to evaluate the corrosion kinetics under sliding. Moreover, further studies are also needed in order to deeply characterize the surfaces, sub-surfaces and wear debris, to quantify the total amount material degradation as a function of testing parameters simulating the in vivo conditions.

\section{Conclusions}

Anodic treatment of Ti6Al4V surfaces in a mixture of $1 \mathrm{M}$ $\mathrm{H} 2 \mathrm{SO} 4$ and $0.08 \mathrm{M}$ HF electrolyte under a constant voltage of 20 $\mathrm{V}$ during $5 \mathrm{~min}$ resulted with the formation of randomly organized nanotubes, whereas increasing the time to $60 \mathrm{~min}$ led to the 
formation of self-organized nanotubular structure with increased pore diameter. Under sliding against an alumina ball in PBS, nanostructured surfaces exhibited significantly lower tendency to corrosion as compared to the untreated surfaces where even no significant difference was observed on 60AT samples due to the protecting effect given by the well-adherent $\mathrm{TiO}_{2}$ nanotubular layer.

\section{Acknowledgements}

This study was supported by FCT with the reference project UID/EEA/04436/2013, by FEDER funds through the COMPETE 2020 - Programa Operacional Competitividade e Internacionali zação (POCI) with the reference project POCI-01-0145-FEDER006941, and Procs. $^{\circ}$ 4.4.1.00 and 99999.008666/2014-08 FCT/ CAPES.

\section{References}

[1] B. Sivakumar, S. Kumar, T.S.N. Sankara, Narayanan, Fretting corrosion behaviour of Ti-6Al-4V alloy in artificial saliva containing varying concentrations of fluoride ions, Wear 270 (2011) 317-324.

[2] V. Babuskaa, O. Moztarzadeh, T. Kubikova, A. Moztarzadeh, D. Hrusak, Z. Tonar, Evaluating the osseointegration of nanostructured titanium implants in anima models: current experimental methods and perspectives (Review), Biointerphases 11 (2016) 30801.

[3] M. Sarraf, E. Zalnezhad, A.R. Bushroa, A.M.S. Hamouda, A.R. Rafieerad, B. NasiriTabrizi, Effect of microstructural evolution on wettability and tribological behavior of TiO2 nanotubular arrays coated on Ti-6Al-4V, Ceram. Int. 41 (2015) 7952-7962.
[4] E. Zalnezhad, S. Baradaran, A.R. Bushroa, A.A.D. Sarhan, Mechanical property enhancement of Ti-6Al-4V by Multilayer thin solid film $\mathrm{Ti} / \mathrm{TiO}_{2}$ nanotubular array coating for biomedical application, Metall. Mater. Trans. A Phys. Metall Mater. Sci. 45 (2014) 785-797.

[5] N.K. Awad, S.L. Edwards, Y.S. Morsi, A review of TiO2 NTs on Ti metal: electrochemical synthesis, functionalization and potential use as bone implants, Mater. Sci. Eng., C 76 (2017) 1401-1412.

[6] M. Mansoorianfar, M. Tavoosi, R. Mozafarinia, A. Ghasemi, A Doostmohammadi, Preparation and characterization of $\mathrm{TiO}_{2}$ nanotube arrays on Ti6Al4V surface for enhancement of cell treatment, Surf. Coat. Technol. 321 (2017) 409-415.

[7] S.A. Alves, S.B. Patel, C. Sukotjo, M.T. Mathew, P.N. Filho, J.-P. Celis, L.A. Rocha, T. Shokuhfar, Synthesis of calcium-phosphorous doped $\mathrm{TiO}_{2}$ nanotubes by anodization and reverse polarization: a promising strategy for an efficient biofunctional implant surface, Appl. Surf. Sci. 399 (2016) 682-701.

[8] B. Ercan, E. Taylor, E. Alpaslan, T.J. Webster, Diameter of titanium nanotubes influences anti-bacterial efficacy, Nanotechnology 22 (2011) 295102.

[9] J. Grotberg, A. Hamlekhan, A. Butt, S. Patel, D. Royhman, T. Shokuhfar, C. Sukotjo, C. Takoudis, M.T. Mathew, Thermally oxidized titania nanotubes enhance the corrosion resistance of Ti6Al4V, Mater. Sci. Eng., C 59 (2016) 677689.

[10] A. Alves, A.L. Rossi, A.R. Ribeiro, F. Toptan, A.M. Pinto, Tribo-electrochemical behavior of bio-functionalized $\mathrm{TiO} 2$ nanotubes in artificial saliva: understanding of degradation mechanisms, Wear 384-385 (2017) 28-42.

[11] E. Matykina, J.M. Hernandez-López, A. Conde, C. Domingo, J.J. De Damborenea, M.A. Arenas, Morphologies of nanostructured $\mathrm{TiO}_{2}$ doped with $\mathrm{F}$ on Ti-6Al-4V alloy, Electrochim. Acta 56 (2011) 2221-2229.

[12] A.F. Yetim, Investigation of wear behavior of titanium oxide films, produced by anodic oxidation, on commercially pure titanium in vacuum conditions, Surf. Coatings Technol. 205 (2010) 1757-1763.

[13] F. Toptan, A. Rego, A.C. Alves, A. Guedes, Corrosion and tribocorrosion behavior of Ti-B4C composite intended for orthopaedic implants, J. Mech. Behav. Biomed. Mater. 61 (2016) 152-163.

[14] S. Oh, C. Daraio, L.-H. Chen, T.R. Pisanic, R.R. Fiñones, S. Jin, Significantly accelerated osteoblast cell growth on aligned TiO2 nanotubes, J. Biomed. Mater. Res. Part A 78A (2006) 97-103. 